\title{
Expressing and functional analysis of mammalian apoptotic regulators in yeast
}

\author{
MT Greenwood ${ }^{*, 1}$ and P Ludovico ${ }^{*, 2}$
}

The ease by which yeast can be manipulated in conjunction with their similarities to cells of more complex metazoans makes many yeast species, particularly Saccharomyces cerevisae, very attractive models for the study of conserved evolutionary processes that occur in eukaryotes. The ability to functionally express heterologous genes in these cells has allowed the development of countless new and elegant approaches leading to detailed structure-function analysis of numerous mammalian genes. Of these, the most informative have been the studies involving the analysis of regulators that have no direct or obvious sequence orthologue in yeast, including members of the Bcl-2 family of proteins, caspases and tumour suppressors. Here we review the field and provide evidence that these studies have served to further understand mammalian apoptosis.

Cell Death and Differentiation (2010) 17, 737-745; doi:10.1038/cdd.2009.177; published online 13 November 2009

\section{Yeast As a Model to Study Mammalian Apoptotic Regulators}

Apoptosis, the best recognized form of programmed cell death, is a physiological mechanism that, when inappropriately controlled, causes several diseases. ${ }^{1}$ Apoptosis is characterized by an orderly pattern of events under regulation of a large diversity of key molecular mediators, such as caspases and the Bcl-2 family members. The large variety of apoptotic regulators, their numerous interactions and their dependency on the cell's genetic makeup and stimuli complicate the analysis of their individual interactions and functions within apoptosis. In the 1990s, yeast cells appeared as an appealing eukaryotic unicellular model system to study mammalian apoptosis-regulator proteins on the basis of their powerful genetic tools. ${ }^{2}$ The exploitation of yeast as a 'clean room' system to study interactions between heterologously expressed regulatory components of apoptotic pathways has yielded new insights into apoptosis as will be discussed later. Nowadays, several studies have shown that yeast cells possess an ancestral endogenous programmed cell death machinery. In effect, although Bcl-2 family members, caspases or p53, seem to be absent from yeast genome, some apoptotic regulators, such as cytochrome $c$ (Cyt $c)$, apoptosis inducing factor (Aif), HtrA/OMI and endonuclease $G$ have been implicated in yeast cell death, supporting the hypothesis that mitochondrial precursors have evolved to possess a battery of molecules capable of killing host cells. ${ }^{3}$ In addition, yeast cells have a metacaspase, a caspase-like protein, ${ }^{4}$ which shares structural and mechanistic features with metazoan caspase ${ }^{5}$ and has been implicated in the majority of yeast apoptotic scenarios described so far. ${ }^{6}$ In this context, heterologous expression of mammalian killers in yeast is even more exciting as it can serve to uncover new genes or unknown interactions between common apoptotic regulators/ pathways and drugs that modulate the cell death pathways of higher eukaryotes. In this review, we examine and revisit the pioneering studies on the heterologous expression and functional analysis of Bcl-2 family members, caspases and tumour suppressors genes in yeast cells.

\section{Analysis of Heterologous Bax Expression in Yeast}

Bax-induced cell death in yeast. Mammalian mitochondriacentered apoptosis is thought to be largely regulated by the Bcl2 family of proteins. ${ }^{7}$ These proteins are identified by the presence of one or more common Bcl-2 homology $(\mathrm{BH})$ domains. The approximately $30 \mathrm{Bcl}-2$ family members can be classified on the basis of their different functions, as well as the corresponding $\mathrm{BH}$ domains they contain in anti-apoptotic proteins (e.g. Bcl-2, Bcl-xL and $\mathrm{Mcl}-1$ ) and pro-apoptotic proteins (e.g. Bax and Bak). A number of other $\mathrm{Bcl}-2$ members contain a single $\mathrm{BH} 3$ domain (so-called BH3-only proteins, e.g. Bad, Bid, Noxa and Puma) and are largely proapoptotic by virtue of their ability to serve as modulators of the

\footnotetext{
${ }^{1}$ Department of Chemistry and Chemical Engineering, Royal Military College (RMC), PO Box 17000, Station Forces, Kingstone, Ontario, Canada K7K 7B4 and ${ }^{2}$ Life and Health Sciences Research Institute (ICVS), School of Health Sciences, University of Minho, Campus de Gualtar, Braga 4710-057, Portugal

${ }^{*}$ Corresponding authors: P Ludovico, Life and Health Sciences Research Institute (ICVS), School of Health Sciences, University of Minho, Campus de Gualtar, Braga 4710-057, Portugal Tel: + 351253 604812; Fax: + 351253 604809; E-mail: pludovico @ecsaude.uminho.pt or MT Greenwood, Department of Chemistry and Chemical Engineering, Royal Military College (RMC), PO Box 17000, Station Forces, Kingston, Ontario, Canada K7K 7B4. Tel: + 0016136416000 ext. 3575; Fax: + 001613542 9489; E-mail: michael.greenwood@rmc.ca

Keywords: Bcl-2 family members; caspases; tumour suppressors; apoptosis; Bax-mediated cell death

Abbreviations: Cyt c, Cytochrome C; siRNAs, Small interference RNAs; ROS, Reactive oxygen species; IAPs, Inhibitor of apoptosis proteins; Yca1, Yeast metacaspase 1; Aif, Apoptosis inducing factor; MOM, Mitochondrial outer membrane

Received 24.7.09; revised 12.10.09; accepted 12.10.09; Edited by D Vaux; published online 13.11.09
} 
other Bcl-2 proteins. ${ }^{7-8}$ When subjected to appropriate proapoptotic stimuli, there is a concerted interaction of the subset of $\mathrm{Bcl}-2$ proteins that are present or produced in an individual cell. As a result, there is a decrease in the function of the antiapoptotic Bcl-2 proteins and a concomitant increase in the activity of the pro-apoptotic $\mathrm{Bcl}-2$ proteins that when activated are inserted in the mitochondrial outer membrane (MOM), eliciting a number of mitochondrial functional alterations, such as the release of apoptosis-promoting factors including Cyt $c{ }^{8}$ ultimately leading to the cell's demise.

The use of human and mouse cell lines that have one or more deleted $\mathrm{BCl}$-2-encoding genes, as well as the use of other tools to decrease the repertoire of functional $\mathrm{Bcl}-2$ proteins, such as drug inhibitors, dominant-negative peptides and specific siRNAs, facilitates the study of Bcl-2 protein interactions. ${ }^{9-10}$ An alternative approach to the study of $\mathrm{Bcl}-2$ proteins is to use a model system such as yeast. ${ }^{11-12}$ Although yeast does not seem to contain Bcl-2 proteins, it was nevertheless demonstrated by several groups that expression of activated Bax leads to cell death. In 1994, Sato et al. ${ }^{13}$ used a yeast two-hybrid system to examine Bax-Bcl-2 interactions and accidentally found that Bax confers a lethal phenotype when expressed in Saccharomyces cerevisiae. Importantly, Bax lethality can be overcome by co-expressing the anti-apoptotic proteins: Bcl-2 or Bcl-xL. Subsequently, Bax expression was also shown to induce cell death in a variety of different yeast species, such as Schizosaccharomyces pombe, Pichia pastoris, Kluyveromyces lactis and Candida albicans. ${ }^{14-19} \mathrm{~S}$. cerevisiae Bax-induced cell death was described as resembling autophagy with dismantling of organelles and cytoplasmatic vacuolization, and thus it was suggested that these toxic effects were mainly due to the intrinsic toxicity of the Bax protein, probably mediated by its ability to promote channel-pore formation. ${ }^{2}$ Later, Ligr et al. ${ }^{20}$ showed that a series of morphological changes in yeast cells expressing human Bax are similar to those observed in apoptotic metazoan cells namely chromatin condensation, DNA fragmentation, exposition of phosphatidylserine, plasma blebbing and reactive oxygen species (ROS) production. Typical apoptotic features, such as chromatin condensation, have also been reported after Bax expression in $P$. pastoris ${ }^{19}$ and S. pombe. ${ }^{16}$ Similarly to mammalian cells, Bax expressed in yeast cells was shown to localize to mitochondria ${ }^{21}$ and to induce several mitochondrial dysfunctions, ${ }^{22}$ such as changes in mitochondrial membrane potential ${ }^{21}$ and release of Cyt $c .{ }^{22}$ In accordance, Bax killing efficiency is enhanced under respiratory conditions as compared with fermentative conditions. $^{21}$

Analogous to studies performed in mammalian cells, anti-apoptotic members of the Bcl-2 family, including $\mathrm{Bcl}-2$, $\mathrm{Bcl}-\mathrm{xL}$ and $\mathrm{Mcl}-1$, suppress the lethal function of Bax in yeast, whereas the pro-apoptotic protein, Bcl-xs, and various deletion mutants of $\mathrm{Bcl}-2$ that are non-functional in mammalian cells do not. ${ }^{13-14,23}$ Interestingly, even some mutants of $\mathrm{Bcl}-2$, which retain the ability to bind Bax but which are deficient in anti-apoptotic activity in mammalian cells are similarly unable to suppress Bax-mediated lethality in budding yeast, ${ }^{23}$ implying that the mere binding of anti-apoptotic $\mathrm{Bcl}-2$ family proteins to Bax is insufficient to abrogate its deadly function in yeast. These parallels between the effects of wild- type and mutant Bcl-2 family proteins on yeast cell death suggest that some aspects of the function of these proteins may be translatable into less complex organisms and constitute a strong piece of evidence favoring that Bax-induced cell death is not the result of a nonspecific cytotoxicity. Nevertheless, the specificity of Bax function in yeast cells is still questioned. For example, the expression in yeast of both mammalian $\mathrm{Bcl}-2$ and the Caenorhabditis elegans orthologue CED-9 inhibited oxidative stressmediated cell death, ${ }^{24}$ and $\mathrm{Bcl}-2$ was able to alleviate the oxidant hypersensitivity of yeast cells lacking the gene

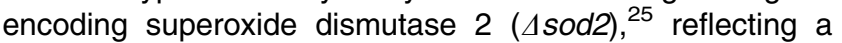
protective function independent of Bax. The observed Bax-independent effects are not likely to be artifactual, as some anti-apoptotic members of the Bcl-2 family were previously reported to have an antioxidant function in mammalian cells. ${ }^{26}$ Studies in the strictly aerobic yeast $K$. lactis showed that co-expression of $B c /-x L$ prevented Bax toxicity but did not prevent the production of ROS, suggesting that, at least in K. lactis cells, ROS are not crucial mediators of Bax-induced cell death and that the antiapoptotic function of $\mathrm{Bcl}-\mathrm{xL}$ is not limited to its antioxidant property. ${ }^{17}$ Levine et al. ${ }^{27}$ also described that a vesicleassociated membrane protein of Arabidopsis thaliana suppresses Bax-induced cell death in yeast downstream of oxidative burst, suggesting that Bax-induced cell death in yeast might occur, at least in part, by modulating the levels of ROS $^{24}$ (Figure 1).

Considerable debate still exists regarding the cellular components in yeast, which are necessary for Bax-specific toxicity. Bax cytotoxicity was shown to be independent of the yeast metacaspase, YCA1. However, it should be noted that Bax-mediated apoptosis using both caspase-dependent and caspase-independent processes has been observed in mammalian systems. ${ }^{28}$ In addition, one cannot exclude a putative role of other yeast proteases that might also have a function in Bax-induced cell death, such as the proteasome, ${ }^{29}$ the mitochondrial AAA-type protease Yme1p, which is activated upon Cyt $c$ release,$^{30-31}$ and vacuolar proteases. Other mechanisms may also exist, for example, several pieces of evidence support the involvement of an autophagic process in Bax-induced cell death in yeast (Figure 1). In effect, initial visualizations of yeast cells expressing Baxindicated an extensive cytoplasmic vacuolization. ${ }^{2,20}$ Later on, it was shown that a strain defective in central vacuole formation and membrane trafficking, due to a mutation in $A R L 1$ gene, was resistant to cell death induced by Bax. These cells do not present the typical ultrastructural autophagic hallmarks similar to wild-type cells upon Bax expression, suggesting that Baxinduced cell death requires efficient membrane trafficking and vacuole formation. ${ }^{32}$ Further clues towards identifying the mechanisms involved are provided by the function of genes corresponding to mutants identified in genetic screens for Bax-resistant cells. All the available evidences suggest that the protein encoded by one such gene Uth1p, participates in an autophagic pathway involving mitochondria, which is reminiscent of the requirements for Bax-induced cell death in yeast ${ }^{33}$ (Figure 1). Thus, phenotypes of cells lacking UTH1 gene also support the observations that resistance to Bax is conferred by defects in autophagic and membrane-trafficking 


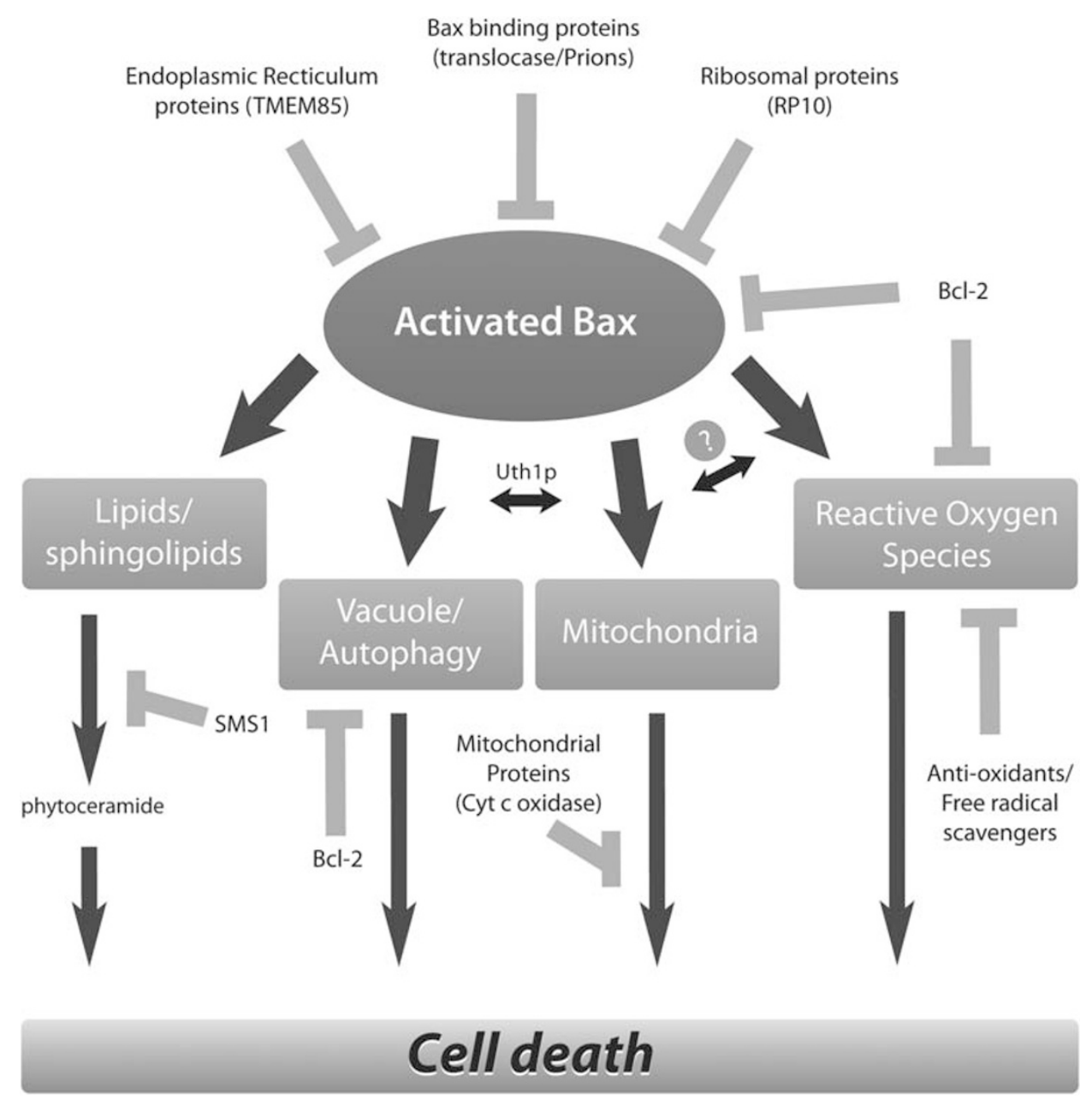

Figure 1 Schematic representation of the effects of heterologously expressed Bax suppressors in yeast

processes. Eight out of the twelve Bax-resistant strains identified in another screen displayed defects in the nutrientrecycling processes associated with autophagy. ${ }^{34}$ Although these later results, combined with the observations of mutants lacking UTH1, provide an interesting link between the vacuolar and mitochondrial effects of Bax, there are other scenarios in which mitochondria and the vacuole seem to act independently and without obvious correlations to each other. ${ }^{34-35}$ In effect, Belhocine et al. ${ }^{34}$ used a mutant strain highly resistant to Bax to screen for genes which overexpression could restore Bax sensitivity. These suppressors promoted Bax sensitivity in a vacuole-dependent but mitochondria-independent manner. ${ }^{34}$ Conversely, another study found that a Bax-inhibiting glutathione $S$-transferase protein, isolated as a high-copy suppressor from a tomato cDNA library, ${ }^{36}$ confers protection to Bax cytotoxicity by replacing the normal mitochondrial, but not the vacuolar, functional parameters. $^{35-36}$

Altogether, the data obtained from the study of Bax-induced cell death in yeast favor the hypothesis that Bax triggers distinct cell death pathways (Figure 1), in a similar manner as in mammalian cells. One pathway is dependent on the autophagic process and another one requires mitochondria. Interestingly, the Bax-protective effects of the anti-apoptotic $\mathrm{Bcl}-2$ protein might be related both with its antioxidant, ${ }^{26}$ as well as with its anti-autophagic effects ${ }^{37}$ observed both in yeast and in mammalian cells. Thus, using yeast-based systems to reconstitute Bax-induced cell death and its abrogation by natural adapters might provide, in the near future, further insights into the function of $\mathrm{Bcl}-2$ family proteins in mammalian cells.

The study of Bax function in yeast. A number of models exist to explain how the structurally complex, largely cytosolic and inactive Bax protein found in healthy cells becomes activated. $^{7}$ The early and now largely disputed rheostat model suggested that $\mathrm{Bax}$ was bound to $\mathrm{Bcl}-2$ and alterations in the levels of either one led to pro- or anti-apoptotic responses. More recent models take into account the observed effects of the BH3-only proteins. Although there is a general picture regarding the function of individual $\mathrm{Bcl}-2$ members, controversies still exist and a large number of questions remain to be answered. ${ }^{7}$ Understanding the nature of the functional interactions between the individual $\mathrm{Bcl}-2$ 
members that lead to the apoptotic responses is made more complicated by the large number of different $\mathrm{Bcl}-2$ members that are expressed in a given cell. As referred above, although yeast does not have endogenous $\mathrm{Bcl}-2$ proteins, it has proven to be a useful in vivo heterologous model for the functional analysis of the interaction between individual $\mathrm{Bcl}-2$ proteins, as these proteins retain their function when expressed in yeast. ${ }^{11-12}$ For example, early on, the expression of $\mathrm{Bcl}-\mathrm{xL}$ mutants unable to bind Bax was shown to nevertheless retain the ability to prevent some of the lethal effects of Bax in yeast. ${ }^{38}$ This was indicative that some of the effects of $\mathrm{Bcl}-2$ proteins did not require heterodimerization with other $\mathrm{Bcl}-2$ proteins. Conversely, early studies on the analysis of Bax mutants in yeast suggested that Bax homodimerization was important for its function. ${ }^{39}$ In effect, the analysis of mutant forms of different $\mathrm{Bcl}-2$ proteins in yeast was important in delineating many aspects of the structural function of Bax including the delineation of the $\mathrm{BH}$ domains, as well as other functional regions such as those involved in mitochondrial targeting. Yeast continues to be a useful model to study the function of $\mathrm{BH} 3$ proteins. For example, yeast was used in a recent study to address the controversial issue of whether the BH3-only protein, Puma, acts as either an activator or a sensitizer in the process of Bax activation. ${ }^{40}$ The study made use of the fact that full-length unaltered Bax (no tag or mutation) when overexpressed in yeast, will not lead to cell death as Bax is not activated. The study clearly demonstrated that coexpression of Puma with inactive Bax leads to increased Cyt $c$ release and cell death. A variety of controls such as the fact that $\mathrm{Bcl}-\mathrm{xL}$ inhibits the lethal effects of the co-expression of Puma and Bax, and that Puma does not enhance the killing effect of the active and lethal BaxD33A mutant, point to the specificity of the observed effects. Thus, Puma is a direct activator of Bax in a process that does not require other $\mathrm{Bcl}-2$ proteins including anti-apoptotic $\mathrm{Bcl}-2$ proteins. It is of interest that full-length unaltered Bax is not lethal in yeast. As in mammalian cells, Bax must be altered or activated in some way for it to be competent to induce cell death. ${ }^{8}$ In mammalian cells, a number of $\mathrm{Bcl}-2$ proteins have been implicated in mediating this activation. ${ }^{7}$ The exact processes as well as the entire repertoire of events that control and are necessary for Bax activation is still being actively investigated. $^{7-8}$ In yeast, genetic alterations of Bax, such as fusing it to other proteins, including LexA or a c-myc epitote, or the introduction of point mutations, such as BaxD33A, seem necessary for its ability to induce apoptosis. ${ }^{13-14,21,40}$ This suggests that yeast cells lack the ability to activate Bax although a systematic evaluation of this concept is yet to be undertaken. Nevertheless, genetic mechanisms may represent common ways to activate Bax. For example, the alternatively spliced variant, $\operatorname{Bax} \beta$, is constitutively active and it may also be able to activate the inactive Bax $\alpha$ variant. ${ }^{41}$ Alternatively, a dominant-negative type splice variant, Bax-w, has also been reported. ${ }^{42}$ Other aspects of Bax function studied in yeast are diverse and include the use of yeast mutants defective in cardiolipin synthesis to determine the importance of this lipid in Bax mitochondrial interaction. ${ }^{43}$ Studies using yeast mutants defective in different genes encoding mitochondrial proteins served to identify the translocase of outer mitochondrial membrane (TOM) complex as being required for the ability of Bax to mediate the release of Cyt $c$ in yeast. ${ }^{44}$ Nevertheless, as with much of the Bax research in other cells, there remain controversies with some of the results obtained in yeast. ${ }^{11}$ For example, there are studies suggesting that TOM is not required for Bax mitochondrial interaction in yeast. ${ }^{45}$ This is not surprising given that the issue of the importance of cardiolipin, TOM as well as other potential Bax receptors on the mitochondria still remains contentious. ${ }^{46}$

Finally, the human autophagy regulator Bcl-2-interacting protein encoded by Beclin 1 contains a functional Bcl-2 $\mathrm{BH} 3$ domain. This gene is of further interest as an apoptotic regulator because it is also a haploid insufficient tumour suppressor. The human Beclin 1 cDNA can complement the starvation-induced autophagic defect in yeast strains lacking the yeast Beclin 1 orthologue called Atg6p. ${ }^{37}$ In addition, expression of human or viral $\mathrm{Bcl}-2$ was shown to inhibit Beclin 1 function in spite of the fact that $\mathrm{Bcl}-2$ does not seem to interact with yeast Atg6p. Pattingre et al. ${ }^{37}$ were able to use this heterologous system to demonstrate that amino-acid substitutions within Bcl-2 or Beclin 1, which abolished their interaction also prevented $\mathrm{Bcl}-2$-mediated inhibition of Beclin 1. Thus in addition to serving as a homologous system to study endogenous apoptotic processes, ${ }^{47,48}$ yeast also serves as an excellent heterologous model system to address specific aspects of mechanisms of apoptosis that are unique to the corresponding process present in mammalian cells. $^{49-50}$

Genetic screens in yeast cells expressing Bax. In addition to the direct study of Bax function, numerous studies using genetic approaches have also proven to be very informative. Using regulatable promoters, such as the galactose-inducible $G A L 1$ promoter, to express activated Bax in yeast generates conditionally lethal strains that have been commonly used as a tool to carry out suicide survival type screens. Such Bax suppressor screens were carried out using cDNA libraries from a number of different mammalian cell types and plant species (Table 1). Most groups have identified multiple clones in each screen. For example, Seo et $a l^{51}$ have identified 24 different Bax suppressors from their screen of a human glioblastoma cDNA library. The functional diversity of different clones was surprising and included sequences involved in signal transduction, redox state, ubiquitination and DNA repair. We found a similar diversity of function in the Bax suppressors identified in our screens of mammalian cDNA libraries. ${ }^{52}$ The functions of many of the identified clones, such as those involved in the metabolism of free radicals, clearly implicate them as antiapoptotic sequences. ${ }^{53}$ In contrast, other clones, such as the small GTPase Ran, require more elaborate scenarios to explain the mechanism by which they inhibit Bax-mediated cell death. ${ }^{54}$ However, there was no known function for TMEM85 before being identified as an anti-apoptotic protein. $^{55}$ Thus the number and the diversity of clones identified as Bax suppressors further serve to highlight the complexity of the apoptotic responses to Bax in yeast, and the usefulness of Bax-expressing yeast as a tool to identify and characterize new anti-apoptotic sequences (Table 1). 
Table 1 Clones capable of preventing Bax-mediated cell death in yeast

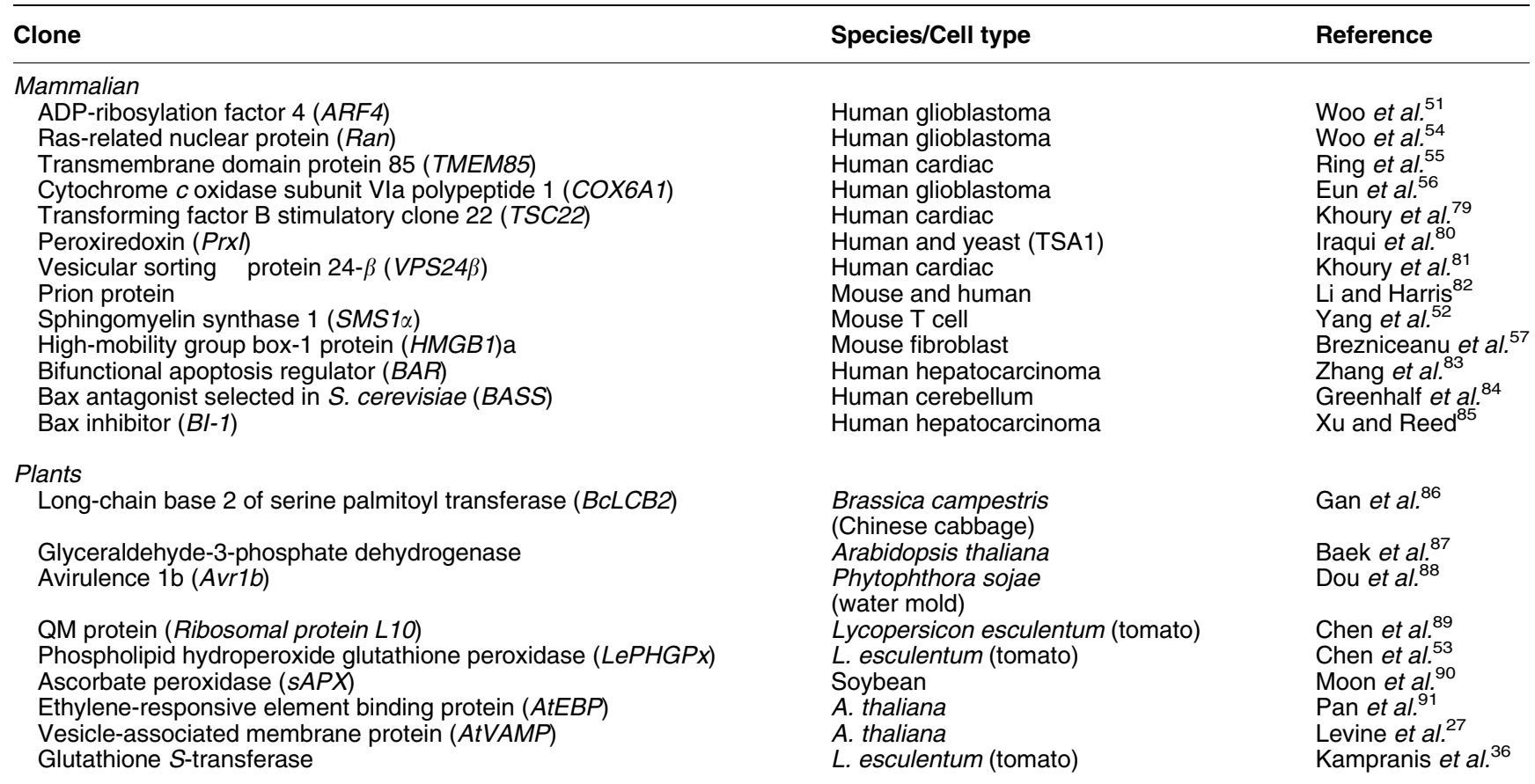

Many of these Bax suppressors, including Ran, $A D P$ ribosylation factor 4, Cyt $c$ oxidase and HMGB1 have already been shown to suppress cell death when overexpressed in mammalian cells. ${ }^{51,54,56-57}$ In addition to screens for suppressors, other researchers have used yeast strains that conditionally express Bax to screen for mutants that are resistant to Bax. ${ }^{33-34,58}$ Such a strategy has served to identify yeast genes, including the gene encoding the mitochondrial FOF1-ATPase proton pump, protein products of which are required for the lethal effects of Bax. ${ }^{58}$ Many Bax-resistant mutants identified were defective in their ability to target Bax to the mitochondria. ${ }^{34,59}$ Using such a Baxresistant strain, a reverse genetic screen was used to identify the C-terminal coding sequence of the yeast OYE2 gene encoding the flavin mononucleotide (FMN) oxidoreductase as a sequence that could restore Bax sensitivity. ${ }^{59}$ Further analysis suggests that Oye $2 p$ interacts with the homologous Oye3p and together they represent an important heterodimeric complex that is involved in modulating apoptotic and anti-apoptotic responses. Thus, as also mentioned above, such genetic strategies also lead to further clues regarding the mechanisms of Bax-mediated cell death.

\section{Analysis of Heterologous Expression of Caspases in Yeast}

Caspases are a family of specific aspartate cysteine proteases that after activation cleave a wide range of substrates, including other caspases, behaving as crucial mediators of apoptosis. The family of caspases encompasses several members that can be divided, according to their structure and function, into initiators and effectors. Initiator caspases are responsible for eliciting the apoptotic pathways making a bridge between the adapter proteins and the effector caspases, the executioners of the apoptotic program. ${ }^{60}$ The attractiveness of yeast as a eukaryotic model cell for molecular genetic analyses of apoptosis was also reflected in its use for the study of expressed human caspases based on the analysis of a 'synthetic phenotype'. Expression of caspase- 3 in the yeasts $P$. pastoris ${ }^{60}$ and $S$. pombe ${ }^{61}$ resulted in its auto-activation, after reaching a very high concentration, and in the inhibition of yeast cell growth ${ }^{61}$ and $S$. pombe cell death associated with DNA degradation. ${ }^{62}$ In contrast, the expression of human caspase-3 in the yeast $S$. cerevisiae did not result in its auto-activation and did not impair cell growth or survival, suggesting a lack of zymogen processing and/or caspase activity. ${ }^{63-64}$ To circumvent the observed lack of caspase- 3 auto-activation, the large and the small subunits of caspase-3 were co-expressed allowing the intracellular assembly of active protease, ${ }^{63}$ which resulted in the complete loss of proliferative capacity of cells that nevertheless still retained the ability to efficiently exclude the vital dye trypan blue $^{64}$ (Figure 2).

The use of yeast-based systems to understand caspases regulation was further supported by the ability to model, in yeast cells, human caspases activity through natural adapters. In effect, the cytotoxicity of caspase-3 can be abolished not only when mutant forms of the catalytic domain of caspase-3 are expressed but also when genes encoding specific inhibitors, such as the baculovirus protein p35 or inhibitor of apoptosis proteins (IAPs), are coexpressed. ${ }^{62,64-65}$ The co-expression of different human IAPs is able to suppress caspase- 3 cytotoxic effects in yeast with 


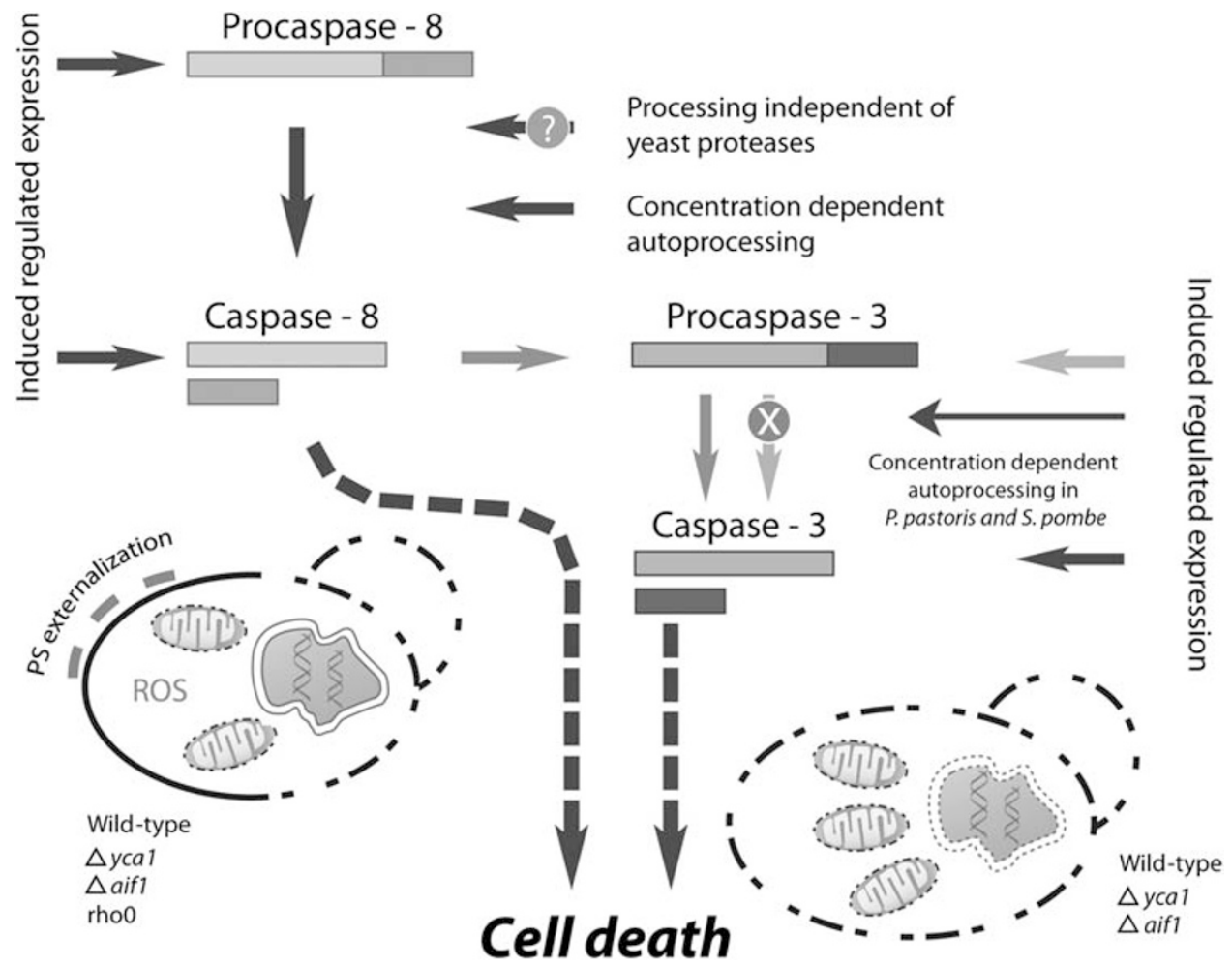

Figure 2 Study and functional analysis of heterologous expression of caspases in yeast

differing magnitudes for different members, with XIAP as the most effective one and survivin being less efficient, which was also confirmed, in parallel, in mammalian cells. ${ }^{64}$ Consistently, another set of experiments using yeast-based systems showed that the mammalian IAP homologues, MIHB and $\mathrm{MIHC}$, were much less effective than MIHA or p35 in protecting against the toxicity of caspases. ${ }^{65}$ The inhibition of caspase activity promoted by mammalian IAPs is also reverted in yeast when IAP antagonist proteins, such as DIABLO/Smac, HID and GRIM are co-expressed. ${ }^{65}$

As mentioned above human caspase activation in yeast requires either their auto-activation by high expression levels or natural activators such as other caspases or Apaf-1. In effect, co-expression of procaspase- 9 and procaspase-3, two initiator caspases, in yeast was not toxic; however, when active Apaf- 1 is also expressed, it causes death of yeast cells, suggesting that Apaf- 1 activates procaspase- 9 , which in turn activates procaspase- 3 , demonstrating that is also possible to reconstitute the Apaf-1-activated pathway in yeast. ${ }^{65}$ An elegant study by Kang et al. ${ }^{63}$ simultaneously addressed the regulation of multiple human caspases activation in the yeast 5 . cerevisiae. The authors expressed human caspase- $8 \beta$, $-10,-3$ and -6 to investigate the autocatalytic and sequential proteolytic processing of these zymogens. Regulated expression of caspase-3 or -10 alone in yeast had no detectable effect on cell viability, suggesting, as previously demonstrated for caspase-3, ${ }^{61-64}$ a lack of zymogen processing. In contrast, the expression of caspase- $8 \beta$ was extremely toxic and its auto-activation was always accompanied by the appearance of a small $\mathrm{N}$-terminal fragment that, although insufficient to catalyse the maturation of procaspase- $8 \beta$, might be the result of a yeast-encoded proteolytic activity. ${ }^{63}$ This hypothesis was discarded on the basis of the observation that caspase- $8 \beta$ cytotoxicity is abrogated when a catalytically inactive mutant form is expressed. ${ }^{63}$

Only recently have the effects of heterologously expressing caspases been analysed with regards to their potential relationship to the yeast endogenous apoptotic regulators, such as Yca1p and apoptosis-inducing factor (Aifp). The expression of active mammalian, insect and nematode caspases was shown to cause damage to yeast organelles and lead to a reduction in clonogenic survival, in a manner independent of Yca1p and Aif1p. ${ }^{66}$ Particularly, it was found that expression of active human caspase-3 and -8 induced a disruption of cellular membranes leading to damage of the plasma membrane, loss of nuclei integrity and mitochondrial structure but without evidence of DNA damage, as revealed by a TUNEL-negative phenotype ${ }^{66}$ (Figure 2). Unlike what is observed in mammalian cells, the authors found that active heterologously expressed caspase- 3 and -8 were unable to cleave actin, this, in spite of the fact that yeast actin retains the conserved cleavage sequence for caspase- $3 .{ }^{66}$

Very recently, Lisa-Santamaria et al. ${ }^{67}$ further explored the effect of the heterologous expression of the human initiator caspases-8 and -10 in 5 . cerevisiae. It was shown that their cytotoxic effects culminate in cell death with an apoptotic phenotype characterized by production of ROS, chromatin condensation and phosphatidylserine externalization (Figure 2). In agreement with the results obtained in the previous study on caspase- $8,{ }^{66}$ the authors found that 
caspase-8- and -caspase-10-induced lethality is independent of Yca1p, Aif1p and of functional mitochondria, as revealed by rho $^{-}$mutants. ${ }^{67}$ In addition, yeast cells expressing human caspase-10 displayed an increased vacuolization suggesting that an autophagic process might have been activated. Other intracellular alterations, such as disorganization of the actin cytoskeleton and aberrations within the endoplasmic reticulum lumen, were also associated with caspase-10 expression. ${ }^{67}$ Altogether it seems clear that yeast could also provide an excellent opportunity to study the regulation of human caspases through the reconstitution of multiple caspases pathways or the co-expression of natural caspase activators/ inhibitors. Yeast-based systems might not only give new insights on the regulation of the different caspases activities but might also reveal important roles of these proteases not only in cell death but also in cell life.

\section{Analysis of Tumour Suppressors in Yeast}

Tumour suppressor genes encode gatekeeper proteins that serve to regulate cell cycle and cell death and, therefore, they are of critical importance in regulating cell fate. ${ }^{68}$ The heterologous expression of many human genes encoding a range of different tumour suppressors in yeast has served as a useful system to characterize their structure and function. ${ }^{69}$ Yeast has also proven to be an excellent model system to study tumour suppressor genes for which it does not have orthologues, including p53, PTEN and BRAC1 (Table 2). ${ }^{69-72}$ Studies on the p53 tumour suppressor exemplify the versatility of yeast to study different aspects of these mammalian genes. ${ }^{69}$ For the most part, the early studies focused on the use of yeast cells as naive or blank cells in which to analyse p53. In accordance with its known function as a transcription factor, early experiments were thus able to show that the p53 could function as a sequence-specific transcription factor in yeast. ${ }^{72}$ A variety of p53-responsive reporter genes and detection systems have been and continue to be developed and exploited to, among other things, identify and characterize tumour-associated p53 mutants. $^{69,72}$

Although the transcriptional activation function of p53 can account for a number of its functions as a cellular gatekeeper, it is clear that p53 also has numerous other cytoplasmic roles. ${ }^{73}$ For example, p53 is thought to translocate to the mitochondria in response to stresses, induce mitochondrial membrane permeabilization and consequently induce apoptosis by causing the release of pro-apoptotic factors. ${ }^{73}$ Similarly, the analysis of p53 in yeast suggested that p53 also carries out other non-transcriptional functions. ${ }^{69}$ For example, high levels of p53 expression inhibited cell cycle progression in both fission and budding yeast. ${ }^{74-75}$ In S. cerevisiae, this inhibition is enhanced by the heterologous expression of the human cell cycle regulator protein kinase cdc2, whereas in S. pompe the inhibitory effects of p53 are abrogated by the overexpression of cell cycle regulator protein phosphatase cdc25. Thus, p53 interacts with endogenous proteins to regulate cell cycle progression in yeast. These early studies seem to have uncovered a bona fide effect of p53 because a recent study has reported that p53 regulates cell cycle progression in mammalian cells by interacting with cdc25. ${ }^{76}$ Although it is quite clear that there is no direct orthologue of $p 53$ in the yeast genomes, these and various other studies ${ }^{77}$ suggest that a functional homologue to p53 is likely to exist in yeast. Although alternative explanations exist, the ability of these heterologous human apoptotic regulators to function in yeast is largely taken as evidence for the underlying similarities in the regulation of apoptosis in yeast and mammalian cells.

Finally, the effects of high levels of p53 expression in yeast have recently been revisited in light of the now well-accepted paradigm of yeast apoptosis. ${ }^{47}$ It was found that p53 expressed from a strong galactose-inducible promoter results in cell death that has many of the characteristics of apoptosis, including phosphatidylserine exposure, DNA strand breaks and the accumulation of ROS. Analysis of gene expression profiles, by differential display, in yeast cells expressing p53 served to identify a decrease in the expression of the genes encoding thioredoxin (TRX1/2). The thioredoxin genes are stress-inducible genes that offer protection against ROS, and like other antioxidant encoding genes they have roles as antiapoptotic regulators. Thus, p53 may induce apoptosis, in part, by downregulating anti-apoptotic regulators. Observations in mammalian cells also support this later idea, as previous studies have made associations between alterations in $\operatorname{Tr} x$ expression in tumours in general, as well as in tumours with mutant $p 53$ genes. ${ }^{77}$ Earlier studies had noticed a link between oxidative stress and p53 function in yeast. ${ }^{78}$ It was reported that there was loss of the transcriptional factor activity of p53 in yeast strains lacking the thioredoxin reductase 1 (TRR1) gene. This observation was originally

Table 2 Mammalian tumour suppressor genes functionally expressed in yeast

\begin{tabular}{|c|c|c|c|}
\hline Tumour suppressor & Major effects of overexpression & Yeast orthologue & Reference \\
\hline $\begin{array}{l}\text { Protein } 53(p 53) \\
\text { B-cell CLL/lymphoma } 2(B c l-2) \\
\text { Phosphatase and tensin homologue } \\
(P T E N) \\
\text { Breast Cancer } 1(B R C A 1) \\
\text { Retinoblastoma }(R B) \\
\text { Beclin-1 } \\
\text { Cyclin-dependent kinase (CDK4) } \\
\text { MutL homologue 1, colon cancer, } \\
\text { nonpolyposis type } 2(E . \text { coll) }(M L H 1)\end{array}$ & $\begin{array}{l}\text { Induces apoptosis } \\
\text { Inhibits Bax-dependent and -independent apoptosis } \\
\text { Reconstitution of the mammalian PI3K/PTEN/Akt } \\
\text { signalling cascades } \\
\text { Inhibition of yeast growth } \\
\text { Enhances Hec1p chromosomal segregation } \\
\text { Induces autophagy; Inhibited by human Bcl-2 } \\
\text { Inhibition of yeast growth } \\
\text { Increases mutation rate }\end{array}$ & $\begin{array}{l}\text { No } \\
\text { No } \\
\text { No } \\
\text { No } \\
\text { No } \\
\text { ATG6 } \\
\text { CDC28 } \\
\text { MLH1 }\end{array}$ & $\begin{array}{l}\text { Hadj Amor et al. } \\
\text { Ligr et al. }^{20} \\
\text { Rodriguez-Escudero et al. } \\
\text { Humphrey et al. }{ }^{71} \\
\text { Zheng et al. }^{93} \\
\text { Pattingre et al. } \\
\text { Moorthamer et al } \\
\text { Shimodaira et al. }{ }^{95}\end{array}$ \\
\hline
\end{tabular}

\footnotetext{
${ }^{a}$ Although there is no sequence orthologue to $p 53$ or $\mathrm{Bcl}-2$ in yeast, there is evidence to suggest that functional orthologues may exist
} 
ascribed to an increased oxidative stress-mediated loss in p53 structure in the yeast mutant. More likely, there is a direct link between the apoptotic function of p53 and the oxidative state of the cell. Thus, yeast may serve as an excellent model to study the multitude and growing roles of p53 as an apoptotic regulator.

\section{Conclusions}

More than one decade ago, scientists decided to exploit yeast not only to understand how a cell lives but also to get new insights about how a cell dies. Yeast were used as natural knockout cells to reveal the structure and function of apoptotic regulators, such as Bcl-2 members, caspases or tumour suppressors without the interference of the complex network of proteins involved in apoptosis. These approaches based on the analysis of a 'synthetic phenotype' produced relevant insights about the regulation and molecular interactions of crucial apoptotic regulators. It was also possible to reconstitute in yeast cells several different pathways involving these molecular apoptotic regulators highlighting that yeast will continue to be a powerful system for the expression and functional analysis of mammalian apoptotic regulators.

\section{Conflict of interest}

The authors declare no conflict of interest.

Acknowledgements. We apologize to the researchers whose studies were not cited or discussed in this review. We thank Hilário Trindade and Pedro Trindade for their help on graphical design of the schemes.

1. Gupta S, Kass GE, Szegezdi E, Joseph B. The mitochondrial death pathway: A promising therapeutic target in diseases. J Cell Mol Med 2009; 13: 1004-1033.

2. Matsuyama S, Nouraini S, Reed JC. Yeast as a tool for apoptosis research. Curr Opin Microbiol 1999; 2: 618-623.

3. Gourlay CW, Du W, Ayscough KR. Apoptosis in yeast-mechanisms and benefits to a unicellular organism. Mol Microbiol 2006; 62: 1515-1521.

4. Uren AG, O'Rourke K, Aravind LA, Pisabarro MT, Seshagiri S, Koonin EV et al. Identification of paracaspases and metacaspases: two ancient families of caspase-like proteins, one of which plays a key role in MALT lymphoma. Mol Cell 2000; 6: 961-967.

5. Vercammen D, Declercq W, Vandenabeele P, Van Breusegem F. Are metacaspases caspases? J Cell Biol 2007; 179: 375-380.

6. Mazzoni C, Falcone C. Caspase-dependent apoptosis in yeast. Biochim Biophys Acta 2008; 1783: 1320-1327.

7. Chipuk JE, Green DR. How do BCL-2 proteins induce mitochondrial outer membrane permeabilization? Trends Cell Biol 2008; 18: 157-164.

8. Lalier L, Cartron PF, Juin P, Nedelkina S, Manon S, Bechinger B et al. Bax activation and mitochondrial insertion during apoptosis. Apoptosis 2007; 12: 887-896.

9. Garrofe-Ochoa X, Melero-Fernandez de Mera RM, Fernandez-Gomez FJ, Ribas J, Jordan J, Boix J. BAX and BAK proteins are required for cyclin-dependent kinase inhibitory drugs to cause apoptosis. Mol Cancer Ther 2008; 7: 3800-3806.

10. Kang MH, Reynolds CP. Bcl-2 inhibitors: targeting mitochondrial apoptotic pathways in cancer therapy. Clin Cancer Res 2009; 15: 1126-1132.

11. Khoury CM, Greenwood MT. The pleiotropic effects of heterologous Bax expression in yeast. Biochim Biophys Acta 2008; 1783: 1449-1465.

12. Priault M, Camougrand N, Kinnally KW, Vallette FM, Manon S. Yeast as a tool to study Bax/mitochondrial interactions in cell death. FEMS Yeast Res 2003; 4: 15-27.

13. Sato T, Hanada M, Bodrug S, Irie S, I wama N, Boise LH et al. Interactions among members of the Bcl-2 protein family analyzed with a yeast two-hybrid system. Proc Natl Acad Sci USA 1994; 91: 9238-9242.

14. Greenhalf W, Stephan C, Chaudhuri B. Role of mitochondria and C-terminal membrane anchor of Bcl-2 in Bax induced growth arrest and mortality in Saccharomyces cerevisiae. FEBS Lett 1996; 380: 169-175.

15. Ink B, Zornig M, Baum B, Hajibagheri N, James C, Chittenden T et al. Human Bak induces cell death in Schizosaccharomyces pombe with morphological changes similar to those with apoptosis in mammalian cells. Mol Cell Biol 1997; 17: 2468-2474.
16. Jurgensmeier JM, Krajewski S, Armstrong RC, Wilson GM, Oltersdorf T, Fritz LC et al. Bax- and Bak-induced cell death in the fission yeast Schizosaccharomyces pombe. Mol Biol Cell 1997; 8: 325-339.

17. Poliakova D, Sokolikova B, Kolarov J, Sabova L. The antiapoptotic protein Bcl-x(L) prevents the cytotoxic effect of Bax, but not Bax-induced formation of reactive oxygen species, in Kluyveromyces lactis. Microbiology 2002; 148 (Pt 9): 2789-2795.

18. De Smet K, Eberhardt I, Reekmans R, Contreras R. Bax-induced cell death in Candida albicans. Yeast 2004; 21: 1325-1334.

19. Martinet W, Van den Plas D, Raes H, Reekmans R, Contreras R. Bax-induced cell death in Pichia pastoris. Biotechnol Lett 1999; 21: 821-829.

20. Ligr M, Madeo F, Frohlich E, Hilt W, Frohlich KU, Wolf DH. Mammalian Bax triggers apoptotic changes in yeast. FEBS Lett 1998; 438: 61-65.

21. Priault M, Camougrand N, Chaudhuri B, Schaeffer J, Manon S. Comparison of the effects of bax-expression in yeast under fermentative and respiratory conditions: investigation of the role of adenine nucleotides carrier and cytochrome c. FEBS Lett 1999; 456: 232-238.

22. Manon S, Chaudhuri B, Guerin M. Release of cytochrome $c$ and decrease of cytochrome $c$ oxidase in Bax-expressing yeast cells, and prevention of these effects by coexpression of Bcl-xL. FEBS Lett 1997; 415: 29-32.

23. Hanada M, Aime-Sempe C, Sato T, Reed JC. Structure-function analysis of Bcl-2 protein. Identification of conserved domains important for homodimerization with $\mathrm{Bcl}-2$ and heterodimerization with Bax. J Biol Chem 1995; 270: 11962-11969.

24. Chen SR, Dunigan DD, Dickman MB. Bcl-2 family members inhibit oxidative stress-induced programmed cell death in Saccharomyces cerevisiae. Free Radic Biol Med 2003; 34: $1315-1325$.

25. Longo VD, Ellerby LM, Bredesen DE, Valentine JS, Gralla EB. Human Bcl-2 reverses survival defects in yeast lacking superoxide dismutase and delays death of wild-type yeast. J Cell Biol 1997; 137: 1581-1588.

26. Hockenbery DM, Oltvai ZN, Yin XM, Milliman CL, Korsmeyer SJ. Bcl-2 functions in an antioxidant pathway to prevent apoptosis. Cell 1993; 75: 241-251.

27. Levine A, Belenghi B, Damari-Weisler H, Granot D. Vesicle-associated membrane protein of Arabidopsis suppresses Bax-induced apoptosis in yeast downstream of oxidative burst. J Biol Chem 2001; 276: 46284-46289.

28. Miller TM, Moulder KL, Knudson CM, Creedon DJ, Deshmukh M, Korsmeyer SJ et al. Bax deletion further orders the cell death pathway in cerebellar granule cells and suggests a caspase-independent pathway to cell death. J Cell Biol 1997; 139: 205-217.

29. Ligr M, Velten I, Frohlich E, Madeo F, Ledig M, Frohlich KU et al. The proteasomal substrate Stm1 participates in apoptosis-like cell death in yeast. Mol Biol Cell 2001; 12: 2422-2432.

30. Manon S, Priault M, Camougrand N. Mitochondrial AAA-type protease Yme1p is involved in Bax effects on cytochrome $c$ oxidase. Biochem Biophys Res Commun 2001; 289: $1314-1319$

31. Ludovico P, Rodrigues F, Almeida A, Silva MT, Barrientos A, Corte-Real M. Cytochrome $c$ release and mitochondria involvement in programmed cell death induced by acetic acid in Saccharomyces cerevisiae. Mol Biol Cell 2002; 13: 2598-2606.

32. Abudugupur A, Mitsui K, Yokota S, Tsurugi K. An ARL1 mutation affected autophagic cell death in yeast, causing a defect in central vacuole formation. Cell Death Differ 2002; 9: 158-168.

33. Camougrand N, Grelaud-Coq A, Marza E, Priault M, Bessoule JJ, Manon S. The product of the UTH1 gene, required for Bax-induced cell death in yeast, is involved in the response to rapamycin. Mol Microbiol 2003; 47: 495-506.

34. Belhocine S, Mbithe C, Dimitrova I, Kampranis SC, Makris AM. Yeast mutants resistant to Bax lethality reveal distinct vacuolar and mitochondrial alterations. Cell Death Differ 2004; 11: 946-948.

35. Kilili KG, Atanassova N, Vardanyan A, Clatot N, Al-Sabarna K, Kanellopoulos PN et al. Differential roles of tau class glutathione $S$-transferases in oxidative stress. J Biol Chem 2004; 279: 24540-24551.

36. Kampranis SC, Damianova R, Atallah M, Toby G, Kondi G, Tsichlis PN et al. A novel plant glutathione S-transferase/peroxidase suppresses Bax lethality in yeast. J Biol Chem 2000; 275: 29207-29216.

37. Pattingre S, Tassa A, Qu X, Garuti R, Liang XH, Mizushima N et al. Bcl-2 antiapoptotic proteins inhibit Beclin 1-dependent autophagy. Cell 2005; 122: 927-939.

38. Minn AJ, Kettlun CS, Liang H, Kelekar A, Vander Heiden MG, Chang BS et al. Bcl-xL regulates apoptosis by heterodimerization-dependent and -independent mechanisms. EMBO J 1999; 18: 632-643.

39. Zha H, Aime-Sempe C, Sato T, Reed JC. Proapoptotic protein Bax heterodimerizes with $\mathrm{Bcl}-2$ and homodimerizes with Bax via a novel domain $(\mathrm{BH} 3)$ distinct from $\mathrm{BH} 1$ and $\mathrm{BH} 2$. J Biol Chem 1996; 271: 7440-7444.

40. Gallenne T, Gautier F, Oliver L, Hervouet E, Noel B, Hickman JA et al. Bax activation by the $\mathrm{BH} 3-$ only protein Puma promotes cell dependence on antiapoptotic $\mathrm{Bcl}-2$ family members. $J$ Cell Biol 2009; 185: 279-290.

41. Kim H, Hsieh JJ, Cheng EH. Deadly splicing: Bax becomes Almighty. Mol Cell 2009; 33 $145-146$.

42. Zhou M, Demo SD, McClure TN, Crea R, Bitler CM. A novel splice variant of the cell deathpromoting protein BAX. J Biol Chem 1998; 273: 11930-11936.

43. Gonzalvez F, Bessoule JJ, Rocchiccioli F, Manon S, Petit PX. Role of cardiolipin on tBid and tBid/Bax synergistic effects on yeast mitochondria. Cell Death Differ 2005; 12: $659-667$. 
44. Bellot G, Cartron PF, Er E, Oliver L, Juin P, Armstrong LC et al. TOM22, a core component of the mitochondria outer membrane protein translocation pore, is a mitochondrial recepto for the proapoptotic protein Bax. Cell Death Differ 2007; 14: 785-794.

45. Sanjuan Szklarz LK, Kozjak-Pavlovic V, Vogtle FN, Chacinska A, Milenkovic D, Vogel S et al. Preprotein transport machineries of yeast mitochondrial outer membrane are not required for Bax-induced release of intermembrane space proteins. J Mol Biol 2007; 368: 44-54

46. Ott M, Norberg E, Zhivotovsky B, Orrenius S. Mitochondrial targeting of tBid/Bax: a role for the TOM complex? Cell Death Differ 2009; Jun: 12.

47. Madeo F, Carmona-Gutierrez D, Ring J, Buttner S, Eisenberg T, Kroemer G. Caspasedependent and caspase-independent cell death pathways in yeast. Biochem Biophys Res Commun 2009; 382: 227-231.

48. Eisenberg T, Buttner S, Kroemer G, Madeo F. The mitochondrial pathway in yeas apoptosis. Apoptosis 2007; 12: 1011-1023.

49. Ludovico P, Madeo F, Silva M. Yeast programmed cell death: an intricate puzzle. IUBMB Life 2005; 57: 129-135.

50. Cheng WC, Leach KM, Hardwick JM. Mitochondrial death pathways in yeast and mammalian cells. Biochim Biophys Acta 2008; 1783: 1272-1279.

51. Woo IS, Eun SY, Jang HS, Kang ES, Kim GH, Kim HJ et al. Identification of ADPribosylation factor 4 as a suppressor of $\mathrm{N}$-(4-hydroxyphenyl)retinamide-induced cell death. Cancer Lett 2009; 276: 53-60.

52. Yang Z, Khoury C, Jean-Baptiste G, Greenwood MT. Identification of mouse sphingomyelin synthase 1 as a suppressor of Bax-mediated cell death in yeast. FEMS Yeast Res 2006; 6: 751-762.

53. Chen S, Vaghchhipawala Z, Li W, Asard H, Dickman MB. Tomato phospholipid hydroperoxide glutathione peroxidase inhibits cell death induced by Bax and oxidative stresses in yeast and plants. Plant Physiol 2004; 135: 1630-1641.

54. Woo IS, Jang HS, Eun SY, Kim HJ, Ham SA, Lee JH et al. Ran suppresses paclitaxelinduced apoptosis in human glioblastoma cells. Apoptosis 2008; 13: 1223-1231.

55. Ring G, Khoury CM, Solar AJ, Yang Z, Mandato CA, Greenwood MT. Transmembrane protein 85 from both human (TMEM85) and yeast (YGL231c) inhibit hydrogen peroxide mediated cell death in yeast. FEBS Lett 2008; 582: 2637-2642.

56. Eun SY, Woo IS, Jang HS, Jin H, Kim MY, Kim HJ et al. Identification of cytochrome $c$ oxidase subunit $6 \mathrm{~A} 1$ as a suppressor of Bax-induced cell death by yeast-based functional screening. Biochem Biophys Res Commun 2008; 373: 58-63.

57. Brezniceanu ML, Volp K, Bosser S, Solbach C, Lichter P, Joos S et al. HMGB1 inhibits cell death in yeast and mammalian cells and is abundantly expressed in human breast carcinoma. FASEB J 2003; 17: 1295-1297.

58. Matsuyama S, Xu Q, Velours J, Reed JC. The Mitochondrial F0F1-ATPase proton pump is required for function of the proapoptotic protein Bax in yeast and mammalian cells. Mol Cell 1998; 1: 327-336.

59. Odat O, Matta S, Khalil H, Kampranis SC, Pfau R, Tsichlis PN et al. Old yellow enzymes, highly homologous FMN oxidoreductases with modulating roles in oxidative stress and programmed cell death in yeast. J Biol Chem 2007; 282: 36010-36023.

60. Ho PK, Hawkins CJ. Mammalian initiator apoptotic caspases. FEBS J 2005; 272 5436-5453.

61. Sun J, Bottomley SP, Kumar S, Bird PI. Recombinant caspase-3 expressed in Pichia pastoris is fully activated and kinetically indistinguishable from the native enzyme. Biochem Biophys Res Commun 1997; 238: 920-924.

62. Ryser S, Vial E, Magnenat E, Schlegel W, Maundrell K. Reconstitution of caspasemediated cell-death signalling in Schizosaccharomyces pombe. Curr Genet 1999; 36 (1-2): 21-28.

63. Kang JJ, Schaber MD, Srinivasula SM, Alnemri ES, Litwack G, Hall DJ et al. Cascades of mammalian caspase activation in the yeast Saccharomyces cerevisiae. J Biol Chem 1999; 274: 3189-3198.

64. Wright ME, Han DK, Hockenbery DM. Caspase-3 and inhibitor of apoptosis protein(s) interactions in Saccharomyces cerevisiae and mammalian cells. FEBS Lett 2000; 481: 13-18.

65. Hawkins CJ, Silke J, Verhagen AM, Foster R, Ekert PG, Ashley DM. Analysis of candidate antagonists of IAP-mediated caspase inhibition using yeast reconstituted with the mammalian Apaf-1-activated apoptosis mechanism. Apoptosis 2001; 6: 331-338.

66. Puryer MA, Hawkins CJ. Human, insect and nematode caspases kill Saccharomyces cerevisiae independently of YCA1 and Aif1p. Apoptosis 2006; 11: 509-517.

67. Lisa-Santamaria P, Neiman AM, Cuesta-Marban A, Mollinedo F, Revuelta JL, Jimenez A Human initiator caspases trigger apoptotic and autophagic phenotypes in Saccharomyces cerevisiae. Biochim Biophys Acta 2009; 1793: 561-571.

68. Igney FH, Krammer PH. Death and anti-death: tumour resistance to apoptosis. Nat Rev Cancer 2002; 2: 277-288.

69. Kobayashi T, Wang T, Qian H, Brachmann RK. Genetic strategies in Saccharomyces cerevisiae to study human tumor suppressor genes. Methods Mol Biol 2003; 223: 73-86.
70. Cid VJ, Rodriguez-Escudero I, Andres-Pons A, Roma-Mateo C, Gil A, den Hertog J et al. Assessment of PTEN tumor suppressor activity in nonmammalian models: the year of the yeast. Oncogene 2008; 27: 5431-5442.

71. Humphrey JS, Salim A, Erdos MR, Collins FS, Brody LC, Klausner RD. Human BRCA1 inhibits growth in yeast: potential use in diagnostic testing. Proc Natl Acad Sci USA 1997; 94: 5820-5825.

72. Yousef AF, Xu GW, Mendez M, Brandl CJ, Mymryk JS. Coactivator requirements for p53dependent transcription in the yeast Saccharomyces cerevisiae. Int J Cancer 2008; 122: 942-946.

73. Green DR, Kroemer G. Cytoplasmic functions of the tumour suppressor p53. Nature 2009; 458 (7242): 1127-1130.

74. Nigro JM, Sikorski R, Reed SI, Vogelstein B. Human p53 and CDC2Hs genes combine to inhibit the proliferation of Saccharomyces cerevisiae. Mol Cell Biol 1992; 12: 1357-1365.

75. Bureik M, Jungbluth $A$, Drescher $R$, Wagner $P$. Human $p 53$ restores DNA synthesis control in fission yeast. Biol Chem 1997; 378: 1361-1371.

76. Ruppenthal SL, Noll A, Gotz C, Montenarh M. Interference between p53 and cdc25C in cell cycle regulation. Int J Oncol 2007; 31: 345-352.

77. Hadj Amor IY, Smaoui K, Chaabene I, Mabrouk I, Djemal L, Elleuch H et al. Human p53 induces cell death and downregulates thioredoxin expression in Saccharomyces cerevisiae. FEMS Yeast Res 2008; 8: 1254-1262.

78. Pearson GD, Merrill GF. Deletion of the Saccharomyces cerevisiae TRR1 gene encoding thioredoxin reductase inhibits p53-dependent reporter gene expression. J Biol Chem 1998; 273: 5431-5434.

79. Khoury CM, Yang Z, Li XY, Vignali M, Fields S, Greenwood MT. A TSC22-like motif defines a novel antiapoptotic protein family. FEMS Yeast Res 2008; 8: 540-563.

80. Iraqui I, Faye G, Ragu S, Masurel-Heneman A, Kolodner RD, Huang ME. Human peroxiredoxin Prxl is an orthologue of yeast Tsa1, capable of suppressing genome instability in Saccharomyces cerevisiae. Cancer Res 2008; 68: 1055-1063.

81. Khoury CM, Yang Z, Ismail S, Greenwood MT. Characterization of a novel alternatively spliced human transcript encoding an N-terminally truncated Vps24 protein that suppresses the effects of Bax in an ESCRT independent manner in yeast. Gene 2007; 391 (1-2): 233-241.

82. Li A, Harris DA. Mammalian prion protein suppresses Bax-induced cell death in yeast. J Biol Chem 2005; 280: 17430-17434

83. Zhang H, Xu Q, Krajewski S, Krajewska M, Xie Z, Fuess S et al. BAR: An apoptosis regulator at the intersection of caspases and Bcl-2 family proteins. Proc Natl Acad Sci USA 2000; 97: 2597-2602.

84. Greenhalf W, Lee J, Chaudhuri B. A selection system for human apoptosis inhibitors using yeast. Yeast 1999; 15: 1307-1321.

85. Xu Q, Reed JC. Bax inhibitor-1, a mammalian apoptosis suppressor identified by functional screening in yeast. Mol Cell 1998; 1: 337-346.

86. Gan Y, Zhang L, Zhang Z, Dong S, Li J, Wang Y et al. The LCB2 subunit of the sphingolip biosynthesis enzyme serine palmitoyltransferase can function as an attenuator of the hypersensitive response and Bax-induced cell death. New Phytol 2009; 181: 127-146.

87. Baek $D$, Jin $Y$, Jeong JC, Lee $H J$, Moon $H$, Lee $J$ et al. Suppression of reactive oxygen species by glyceraldehyde-3-phosphate dehydrogenase. Phytochemistry 2008; 69: 333-338

88. Dou D, Kale SD, Wang X, Chen Y, Wang Q, Jiang RH et al. Conserved C-terminal motifs required for avirulence and suppression of cell death by Phytophthora sojae effector Avr1b. Plant Cell 2008; 20: 1118-1133

89. Chen C, Wanduragala S, Becker DF, Dickman MB. Tomato QM-like protein protects Saccharomyces cerevisiae cells against oxidative stress by regulating intracellular proline levels. Appl Environ Microbiol 2006; 72: 4001-4006.

90. Moon H, Baek D, Lee B, Prasad DT, Lee SY, Cho MJ et al. Soybean ascorbate peroxidase suppresses Bax-induced apoptosis in yeast by inhibiting oxygen radical generation. Biochem Biophys Res Commun 2002; 290: 457-462.

91. Pan L, Kawai M, Yu LH, Kim KM, Hirata A, Umeda M et al. The Arabidopsis thaliana ethylene-responsive element binding protein (AtEBP) can function as a dominant suppressor of Bax-induced cell death of yeast. FEBS Lett 2001; 508: 375-378.

92. Rodriguez-Escudero I, Roelants FM, Thorner J, Nombela C, Molina M, Cid VJ. Reconstitution of the mammalian PI3K/PTEN/Akt pathway in yeast. Biochem J 2005; 390 (Pt 2): 613-623.

93. Zheng L, Chen Y, Riley DJ, Chen PL, Lee WH. Retinoblastoma protein enhances the fidelity of chromosome segregation mediated by hsHec1p. Mol Cell Biol 2000; 20: 3529-3537.

94. Moorthamer M, Panchal M, Greenhalf W, Chaudhuri B. The p16(INK4A) protein and flavopiridol restore yeast cell growth inhibited by Cdk4. Biochem Biophys Res Commun 1998; 250: 791-797.

95. Shimodaira $\mathrm{H}$, Filosi $\mathrm{N}$, Shibata $\mathrm{H}$, Suzuki $\mathrm{T}$, Radice $\mathrm{P}$, Kanamaru $\mathrm{R}$ et al. Functional analysis of human MLH1 mutations in Saccharomyces cerevisiae. Nat Genet 1998; 19 : 384-389. 